\title{
Practice-based evidence for children and adolescents: Advancing the research agenda in schools.
}

\section{Citation}

Kratochwill, Thomas R., Kimberly Eaton Hoagwood, Anne E. Kazak, John R. Weisz, Korey Hood, Luis A. Vargas, \& Gerard A. Banez. 2012. "Practice-Based Evidence for Children and Adolescents: Advancing the Research Agenda in Schools." School Psychology Review 41, no. 2: 215-235.

\section{Permanent link}

http://nrs.harvard.edu/urn-3:HUL.InstRepos:34262170

\section{Terms of Use}

This article was downloaded from Harvard University's DASH repository, and is made available under the terms and conditions applicable to Open Access Policy Articles, as set forth at http:// nrs.harvard.edu/urn-3:HUL.InstRepos:dash.current.terms-of-use\#OAP

\section{Share Your Story}

The Harvard community has made this article openly available.

Please share how this access benefits you. Submit a story.

\section{Accessibility}




\section{Practice-Based Evidence for Children and Adolescents:}

\section{Advancing the Research Agenda in Schools}

Thomas R. Kratochwill

Educational and Psychological Training Center

University of Wisconsin-Madison

Kimberly Eaton Hoagwood

Columbia University

Anne E. Kazak

The Children's Hospital of Philadelphia

and The University of Pennsylvania School of Medicine

John R.Weisz

Department of Psychology, Harvard University, and Judge Baker Children's Center, Harvard Medical School

Korey Hood

Cincinnati Children's Hospital Medical Center

Luis A. Vargas

University of New Mexico School of Medicine

Gerard A. Banez

Cleveland Clinic 


\section{Author Notes}

Correspondence concerning this article should be addressed to Thomas R. Kratochwill, Educational and Psychological Training Center, University of Wisconsin-Madison, Madison, WI 53706 E-mail: tomkat@education.wisc.edu

More detailed information on the themes in this paper and the full report from the Task Force may be found at www.apa.org/pi/cyf/evidence.html.

Work on this manuscript was supported by grants (No. MSN103215 and No.

MSN103211) to the first author and the Wisconsin Center for Education Research from the U.S. Department of Education. The views expressed in the manuscript do not reflect those of the U.S. Department of Education or the Wisconsin Center for Education Research. Support to John R. Weisz came from the Catherine T. MacArthur Foundation, National Institute of Mental Health, and the Norlien Foundation. 


\begin{abstract}
The American Psychological Association (APA) Task Force on Evidence-Based Practice (EBP) for Children and Adolescents (2008) recommended a systems approach to enhancing care in order to improve outcomes for children and adolescents with mental health needs and redress persistent systemic problems with the structure of services. Recommendations for enhancing an ecological approach to the adoption and implementation of EBPs are offered through increased attention to practice-based research frameworks for adoption and dissemination. Five criteria are discussed for providing acceptable evidence including, (a) systematic evidence searching and adoption of evidence-based prevention and intervention practices, (b) implementation and adherence to intervention integrity, (c) invoking standards for drawing inferences from interventions, (d) using quality assessments to measure outcomes, and (e) adopting formal data analysis procedures to assess intervention outcomes. Each criterion is illustrated with an example. Future research and policy agendas are outlined.
\end{abstract}




\section{Practice-Based Evidence for Children and Adolescents: Advancing the}

\section{Research Agenda in Schools}

Psychologists working in schools are increasingly aware of the contributions that have occurred in psychology and education around the evidence-based practice (EBP) movement, which has a rich historical context of linking science and clinical care dating back to the work of Lightner Witmer (Kratochwill, Morris, \& Robinson, 2008). Building on the ground-breaking evidence-based intervention work of American Psychological Association (APA) Division 12 and 53 (e.g., Weisz \& Hawley, 2001), the APA initiated a Presidential Task Force on EvidenceBased Practice in 2005. A report of that Task Force emphasized that various forms of research evidence can impact practice and the importance of clinical expertise and judgment in providing psychological care (APA Presidential Task Force on Evidence-Based Practice, 2006). The APA Task Force on Evidence-Based Practice for Children and Adolescents (2008; hereafter called the Task Force) was formed to build on the work of the Presidential Task Force to reduce the research-to-practice gap and promote evidence-based interventions in school psychological services, but with a special focus on the unique factors influencing children, adolescents, and their families.

The Task Force was guided by four principles (see Table 1) to conceptualize the integration of research and practice and a broader systemic orientation to improve overall mental health and educational care. We approached the issues from a broad meta-systemic orientation with the goal of providing a framework that would encompass quality improvement and public health. The components of the framework are outlined in Figure 1. We argued that a metasystems perspective is critical to both understanding children's mental health needs and delivering services with enhanced outcomes. In our Task Force report, we discussed the key 
components of a systems approach for children and adolescents with emotional and behavioral needs and subsequently, outlined key components of this "meta-system" for children (Kazak, et al., 2010). We defined the meta-system as follows:

...we use the term meta-system to refer to the various contexts and environments that surround and influence a child's adaptations and development. The core contexts that typically exert the most direct influence on children include their family; the cultural norms and values of their heritage; their peers; social institutions created to inculcate certain societal values (such as churches or schools); and for children with emotional or behavioral needs, the various systems that society creates to provide services to address these problems (p. 86).

The service systems include pediatric healthcare, specialty mental health, juvenile justice, child protection, and substance abuse settings, and, of course, schools.

Around the time that the EBP movement gained prominence in school psychology, the response to intervention (RtI) initiative was developing in education and has now impacted the provision of school-based psychological practice in major ways. RtI is a system of service delivery through which interventions are delivered that combine services for children in a multitiered prevention framework with ongoing progress monitoring of academic and/or behavioral targets at each of the levels of tiers (Glover, DiPerna, \& Vaughn, 2007; Reschly \& Bergstrom, 2009; VanDerHeyden \& Burns, 2010). In this regard, RtI represents a convergence of evidencebased interventions and several components represented in the tradition of prevention practice (e.g., screening, multi-tiered interventions; see Lembke et al.,[2010] for an example context for reading research within an RtI model). 
In part due to federal mandates and in part, due to political influences, RtI was presented as a format for educational and psychological services to children in regular and special education. Because RtI requires evidence-based interventions as part of its multi-tiered models, even the most reluctant to adopt new frameworks for services have begun to attend to the EBP movement. The current context in which RtI is applied in schools provides a special opportunity for us to feature examples of how the empirical basis of RtI can be improved because it is an excellent example of the limitations of some research in the EBP movement that lacks a strong focus on an evidence base from practice.

The purpose of the current paper is to extend the Task Force recommendations to researchers and practitioners in school psychology and suggest how embracing practice-based evidence research agendas can improve both mental health and educational outcomes for children and families. Specifically, we note how practice-based research evidence work can enhance the scientific basis of psychological and educational preventions and interventions used in schools and has the potential to forge a partnership between researchers and practitioners. We are emphasizing interventions but consider a wide range of psychological activities to fall within the domain of EBPs (e.g., diagnosis, assessment). School psychologists are uniquely positioned to embrace some of the benefits of practice-based research that can advance EBPs to improve children's mental health and academic outcomes.

\section{Schools as Ecological Service Systems for Evidence-Based Practice: Variables Affecting Implementation Efforts}

Among the most challenging issues in advancing EBPs in schools (as well as in other systems) are the variables influencing or inhibiting adoption and dissemination. Although evidence-based prevention and intervention practices share a common challenge related to 
barriers to implementation in educational settings, the clinical trial research base has often neglected implementation factors. In recent years investigators have begun to feature this important focus on implementation variables. For example, Forman, Olin, Hoagwood, Crowe, and Sake (2009) examined factors related to adoption, implementation, and sustainability of evidence-based interventions in schools. They contacted intervention developers of 29 programs listed as EBP on four or more credible registries and conducted a structured phone interview with the developers to identify facilitators and barriers. Teacher and administrator support and training, integrating the interventions within other school curricula, having ongoing technical assistance or coaching to reinforce new skills, and having an economic model to facilitate implementation were important facilitators across the phases of adoption, implementation, and sustainability. Barriers included time, school personnel beliefs about the intervention, competition with priorities already established in the school, and competition with Federal guidelines such as No Child Left Behind (2001).

Forman and colleagues (2009) suggested several critical steps to improve successful implementation and sustainability including, enlisting leadership support with principals and other administrators as well as teachers; identifying financial resources to support continuation of the program; and ongoing coaching, consultation or mentoring along with training to ensure fidelity of the model and maintain integrity during implementation. For example, some research indicates that teachers who report being overloaded and lacking available support persons in a preschool setting predicts higher reports of behavior problems among children (Raver et al., 2009).Thus, it is important to work with staff to explain the program and work commitments, and to deliver professional development, especially with online coursework coupled with mentoring and feedback linked to instructional practices (Landry, Anthony, Swank, \& 
Monseque-Bailey, 2009). In addition, new programs should align with the school context (e.g., philosophy goals, policies, cultural responsiveness), and the program outcomes should be important and visible to the school to optimize sustainability. Finally, staff turnover is a significant impediment to sustaining program integrity and efforts to reduce teacher and administrator turnover are important. Specific organizational interventions that have been found to reduce turnover in other systems might be adapted for use in schools (Glisson \& James, 2002; Glisson, Landsverk, Schoenwald, Kelleher, Hoagwood, Mayberg et al., 2008).

The findings from the Forman et al., (2009) are consistent with research summaries that emphasize a systemic approach to address implementation (Fixsen, Naoom, Blasé, Friedman, \& Wallace, 2005) and underscore how the ecology of practice settings and system issues can be either facilitators or barriers to implementation (see Lochman, Powell, Boxmeyer, Wells, \& Windle, 2009). In the next section we discuss some models for addressing adoption, some relevant research strategies in adoption and dissemination, and emerging needs in this area to advance research in school contexts.

\section{Practice-Based Research as a Framework to Address Implementation and Dissemination}

Traditionally, psychologists have been encouraged to adopt evidence-based assessments and interventions that have been documented in experimental research conducted by researchers. In fact, the EBP movement was premised on the assumption that randomized controlled trials could document effective interventions and practitioners should apply these in practice settings to improve academic and mental health outcomes of children. Research on implementation and dissemination has clearly challenged these perspectives as we noted in our Task Force report and the previous section (see also Flay et al., 2005; Weisz, Doss, \& Hawley, 2006). Increasingly it is becoming recognized that new directions in how the evidence base is established or embellished 
must be considered. There are numerous macro (systemic) and micro (individual) factors that influence the implementation of EBPs. In the school context, educational policies are the backdrop within which characteristics of the school context (staffing, training, technical support) interact with the characteristics of recipients (students, parents, and teachers) to influence implementation outcomes (Raver et al., 2009). Advancing research agendas on implementation and dissemination in school contexts can address how innovative strategies support EBP implementation. Several approaches have been suggested.

One approach to enhancing implementation uses measurement feedback and components-based approaches to quality improvement as a way to improve delivery of EBPs (Bickman, 2009; Chorpita et al., 2008; Chorpita \& Weisz, 2009; Weisz \& Chorpita, 2011). The studies focus on improving concurrent measurement of processes and outcomes and providing feedback to service providers and families about the change process, which is promising because it can enhance the acceptability and use of efficacious interventions, and can be used to identify new promising practices that have not yet been the focus of experimental studies. Other research programs focus on fitting practices seamlessly into schools by attending to the unique ecological context of schools and their naturally-occurring conditions (e.g., focus on learning, individualization, use of teaching and support staff; after school programs) (Atkins et al., 2008; Frazier Cappella, \& Atkins, 2007; Frazier, Adil, Atkins, Gathright, \& Jackson, 2007; Frazier, Formoso, Birman, \& Atkins, 2008), or through participatory action research in which data gathering and interpretation of the findings can guide decisions about a particular practice (Nastasi, Moore, \& Varjas, 2004). As these new promising approaches gain research momentum, their applicability within a range of different school contexts are likely to assist psychologists and other professionals in enhancing the uptake of effective new practices. 
Practice-based evidence research, the focus of this paper, is another agenda that we recommended to improve the knowledge base for adoption and implementation of evidencebased interventions. As a context, practice-based evidence is not unique to psychology as it has been recommended in medicine as a methodology to facilitate practitioner engagement in the research process (e.g., Green, 2006) and is illustrated in nursing (e.g., Shieh, 2006). Basically, the practice-based research process involves practitioners contributing to the knowledge base by collaborating with researchers and sharing information with the research community during the course of providing academic and mental health interventions in typical practice settings (Newman, Kellett, \& Beail, 2003). As an example of why this might be an important issue, in a critique of RtI, Fuchs, Fuchs, and Stecker (2010) provide a rationale for the need for practicebased evidence in a common practice advocated in school problem solving models (e.g., behavioral consultation). These authors argued among other issues, that "...there is little in the literature demonstrating that behavioral consultation improves school achievement or behavior when conducted by practitioners rather than researchers" (p. 314).

Practice-based evidence can be conceptualized within the context of a scientistpractitioner model in which two orthogonal features of science and practice are identified (Lilienfeld, Ammirati, \& David, in press; McFall, 1991). Table 2 features the four dimensions of the relationship between research and practice. Thus, we have a scientific-research focus in which experimental methods are used to develop the knowledge base for practice (e.g., randomized controlled trials, single-case design research). Likewise, non-scientific research (or pseudoscientific) would include a variety of practices that that yield a questionable data base for practice such as testimonials, news media announcements, among other non-science claims (see Lilienfeld et al. in press; and Norcross, Hogan, \& Koocher, 2008 for examples of 
pseudoscientific assertions). Within the practice quadrants, one can be a scientific practitioner or non-scientific practitioner. It is within the scientific practitioner quadrant that we suggest two subcategories, one of which involves a role for developing practice-based evidence.

In the first subcategory we identify the more traditional "scientist-practitioner" who uses scientific research to guide and inform their practice. This category characterizes individuals who embrace EBPs as featured by the Task Force and others (e.g., Hayes, Barlow, \& Nelson, 1999) but is usually not involved in generating new knowledge. In the second subcategory we emphasize a role for individuals who practice school psychology but who want to and could contribute to the scientific knowledge base. This individual would work in collaboration with researchers to implement EBPs in school practice with the primary intent to contribute to the scientific basis of our interventions while providing high priority information on structural and contextual variables.

Practice-based evidence is premised on the assumption that there is a bi-directional relationship between research and practice and transporting EBPs means that practitioners can gather information useful to guiding the knowledge base in a particular area (see Kazdin, 2008; Weisz, 2004; Weisz, Sandler, Durlak, \& Anton, 2005). In embracing this role, evidence can be accumulated to report on effective practices and build a knowledge base that may otherwise be impossible to secure in traditional clinical trials, thereby helping to close the research-to-practice gap.

As knowledge accumulates, practice-based evidence can also be conceptualized as a methodology and process to address components of broad dissemination of EBPs and can be part of ongoing adaptations or modifications of evidence-based interventions to make them more applicable to local ecologies and more culturally responsive. Figure 2 displays three components 
of EBP showing that the approach is guided by a science framework, informed by clinical expertise, and delivered in multiple contexts. It requires practice that involves assessment, intervention, and ongoing monitoring. In this practice context there is valuable information that can be shared with the research community that clinical trials may not always be able to deliver. We are not advocating that traditional clinical trials research be replaced or that conventional transportability research activities be deemphasized. For example, in the prevention literature dissemination can incorporate scaling up, adoption, implementation, and sustainability of prevention and intervention programs (Flay et al., 2005). To scale up a program such factors as training, manuals, organizational infrastructure, and resources must be described. Practice-based research seems especially complementary to help elucidate processes that occur in practice (Huang et al., 2005). Practice-based evidence research strategies can also help as a methodological strategy to further provide information on unique contextual features that require variations from clinical trials on these variables, which in turn, will guide the evidence base for future adoption and implementation.

\section{Standards for Credible Practice-Based Evidence}

Despite some positive conceptual attributes of developing practice-based evidence, some standards must be invoked for generating evidence in order to contribute to the creditability of an intervention and its scientific underpinnings. A threshold for acceptable evidence typically involves some level of certainty about conclusions being drawn from the data. Nevertheless, there is no agreed upon standards criteria for practice-based evidence. There is some consensus that the evidence standards must be relaxed from those invoked for traditional experimental research. Indeed, the concept of doing any research in practice has been problematic with a number of practical and conceptual barriers being salient, especially when critical 
methodological features of research must be incorporated into the process (Kazdin, Kratochwill, \& VandenBos, 1986). Thus, the challenge is to adopt methodologies that have sufficiently sound features to yield some credible information that can be shared with the scientific community and at the same time, allow application in practice that is acceptable, cost-effective, and can be implemented contextually in school systems to generate the kind of knowledge that is useful to guide future adoption and implementation.

Five criteria are advanced here to provide some conceptual guidelines for practice-based evidence (see Kratochwill, 2006, 2007; Kratochwill \& Levin, 2010a for earlier suggestions). Each of these criteria is illustrated in the application of practice-based research and can best be implemented in a partnership between researchers and practitioners. Special attention to elucidating structural and process variables that facilitate or inhibit adoption, implementation, and positive outcomes will be needed. Some of the same methodological tools used in research can be adopted in psychological and educational practice to advance the knowledge base of effective practices and eventually become the focus of controlled research and accomplish the goals noted above. In this regard, we emphasize the reciprocal relationship between practicebased evidence research and more conventional experimental research to support EBP development and implementation.

Evidence searching and adopting evidence-based practices. An important step in developing practice-based evidence is to consider the available evidence base when considering a child's academic and/or mental health issue. This process can be completed by the practitioner and researcher working in concert to select an intervention or practice to meet psychological service needs. Nevertheless, there are actually few guides for psychologists in the knowledge, skills, and process of evidence searching, possibly in that it has traditionally been a specialty in 
library science that is not routinely taught in psychology graduate programs. Realizing this gap in professional training, Falzon, Davidson, and Bruns (2010) provided a framework following five basic steps in the evidence-searching process: “(1) Formulate a clear question about a patient or research issue; (2) search the literature to find the best available evidence; (3) critically appraise the evidence for its validity, accuracy, and usefulness; (4) apply useful findings, integrating them with clinical expertise and patient's characteristics, culture, and preferences; and (5) evaluate the outcomes and, if needed, initiate a refined search" (p. 551).

Falzon et al. (2010) elaborate on the first two steps in the process and invoke the patientintervention-comparison-outcome (PICO) framework for the first step (Norcross, Hogan, \& Koocher, 2008). Table 3 provides a guide for each of the questions that a practitioner can ask for each step of the framework. Note that we have replaced the "Patient" with "Client" to reflect the educational context of this process for a psychologist working in schools (i.e., CICO). Also note that Norcross et al. (2008) add an optional "T" to the PICO components that reflects the type of question that the psychologist is hoping to answer such as issues pertaining to diagnosis, therapy relationships, among many others.

The second step involves searching the literature for the best available evidence and will likely reveal numerous articles, chapters, books, and websites that feature relevant information. As an example, the What Works Clearinghouse (WWC) provides reviews of many educational interventions and is involved in producing intervention reports of developments in a particular area as well as practice guides (see: http://ies.ed.gov/ncee/wwc/reports/).

There are two additional contributions that practice-base evidence can make to the knowledge base. First, although there are a large number of options to review and select EBPs including major web sites that feature programs with varying levels of research support (e.g., the 
Collaborative for Academic Social and Emotional Learning [CASEL.org], National Register of Evidence-Based Programs and Practices [www.nrepp.samhsa.gov], toolkits for implementing EBPs in school and other community settings), many academic and mental health prevention and intervention practices needed for the diversity of school-aged children have not been evaluated in research (e.g., Kazdin, 2008; Kratochwill, 2007; Reynolds \& Shaywitz, 2009). Evaluation practices can yield important information that becomes the focus of future research, completing the cycle of the inter-relationship between practice and research. Second, actual study of the clinical decision-making process in selecting an intervention is under researched and would make a valuable contribution in the future.

Example application. Consider a psychologist who is consulting with a classroom teacher over concerns with managing a classroom of students many of whom are demonstrating serious problematic behavior. The psychologist will immediately be confronted with the question about how to recommend an effective classroom management procedure for this situation. Table 3 provides the CICO framework that reflects addressing the first step in the practice-based evidence process. The psychologist would proceed by searching the literature, appraising it for it quality, apply the findings by considering the cultural and school context, and evaluate the literature given options in this area. At this stage is would be helpful to understand the decisions the psychologist makes in selecting an intervention and why.

In this search process the psychologist would find a number of evidence-based options for preventing and solving classroom management problems (e.g., Freiberg \& Lapointe, 2006; Robinson \& Ricord Griesemer, 2006) and may decide to use the Good Behavior Game as an option especially given its preventative benefits (e.g., Kellam, Rebok, Ialongo, \& Mayer, 1994). The psychologist may also eventually consider a broad-based universal application of positive 
PRACTICE-BASED EVIDENCE FOR CHILDREN AND ADOLESCENTS

behavior support for the school as implemented in an RtI framework (Levis, Newcomer, Trussell, \& Richter, 2006). Thus, the outcome of the evidence searching process has resulted in locating some evidence-base interventions that can be used in addressing this concern. More importantly in our context, the option of studying this process of intervention selection has been provided.

Implementation and Intervention Integrity. There are many issues surrounding implementation with intervention integrity becoming a centerpiece of research in the EBP movement. Traditionally, in practice, once an intervention has been adopted, we know that it must be implemented with integrity (Gresham, 1989; Hagermoser Sanetti \& Kratochwill, 2008). For example, RtI interventions depend on the integrity of implementation across multiple tiers (i.e., implementation of the program/intervention as intended by the program developer). On the one hand, major limitations of implementation (integrity) of evidence-based interventions have been identified in research when assessed (e.g., Klimes-Dougan et al., 2009). Future work needs to provide better documentation that these interventions in research are actually implemented with integrity (Power et al., 2005) and the barriers to and factors influencing implementation with integrity.

The existing base of research evidence suggests that implementation integrity must be actively promoted in clinical trial research across numerous disciplines, including medicine, education, and prevention (Hagermoser Sanetti \& Kratochwill, 2010). Given this backdrop of important factors in research and practice, an important agenda in practice-based evidence research is to study factors that promote and monitor implementation (Hagermoser Sanetti \& Kratochwill, 2008; Mcleod, Southam-Gerow, \& Weisz, 2009), to examine obstacles to intervention integrity in practice settings, and address them so as to ensure positive outcomes. 
The role of the practitioner-researcher in integrity assessment is first to determine if the intervention matches the originally intended protocol and population and if not, what variations were made and with what intervention outcomes. New models of integrity assessment and promotion that are theoretically driven and appropriate for work with teachers are being developed (Hagermoser Sanetti \& Kratochwill, 2010). Although these tools will hopefully facilitate the implementation of interventions, the evidence base still needs to be extended by developing an understanding of the reasons why an intervention was not implemented as intended including the factors featured by Forman et al. (2009) among others.

Example application. Consider the application of Class Wide Peer Tutoring (CWPT; Greenwood, Maheady, \& Carta, 1991), a peer-assisted learning strategy (PALS; Greenwood et al., 1991) in a school hoping to reduce the base rate of reading problems in its students. With considerable research support (see Greenwood, Kamps, Terry, \& Linebarger, 2007 for an overview), CWPT as part of the PALS strategy would require an assessment of whether students are actually engaged in peer-assisted collaborative learning strategies in which they support each other's instruction in classroom settings. In this program students are required to learn academic material as they are arranged in dyads for reading instruction. Various rules guide the actual tutoring behavior and students engage in such peer teaching activities as task presentation, correction, and point and praise awarding for correct responses. Outcome assessment occurs in such areas as phonemic awareness, decoding, and comprehension (see Greenwood, Reynolds, Abbott, \& Tapia, 2004).

In this situation the psychologist will be involved in a variety of integrity monitoring activities some of which may be adopted from the original research projects focused on CWPT and PALS (Greenwood et al., 2007). An important practice-based research contribution can 
occur when assessing integrity of the program in the context of previous scaling up research on CWPT in schools where it was found that several factors influence the process: namely consideration of administrator support, communication patterns among teachers and administrators in program implementation, and early implementation during the school year (Greenwood et al., 2007, Forman et al., 2009). Thus, practice-based research could focus on these issues in implementation and any others that are unique to the context (cultural diversity, high levels of poverty, among others).

Standards for drawing inferences from intervention effects. Among the various candidates for integrating research in practice are qualitative methods (including mixed methods), quasi-experimental group designs, regression discontinuity designs, and single-case research methods. Single-case research designs have been especially strong candidates for this merger and have been featured repeatedly in the psychological literature as compatible with practice (see Barlow, Nock, \& Hersen, 2009; Borckardt et al., 2008; Hayes et al., 1999; Morgan \& Morgan, 2001) due to their quantitative focus, design structure, and focus on the individual. Nevertheless, single-case designs have some major limitations applied in practice (e.g., Kratochwill \& Piersel, 1983), especially when used in their traditional applications where the criterion of replication is featured as a design standard (as in common designs and their variations: $\mathrm{ABAB}$, multiple-baseline, alternating treatment designs).

As an option, single-case design's application in a "case study" format has strong potential for merger with practice-based research (Kazdin, 1982; 2011; Kratochwill, 1985) because these methods allow major validity threats to be considered and may allow some level of causal inference in the absence of design replication standards as required in formal single-case research. These standards are under development and may be a viable option for generation of 
empirical knowledge in research and practice (Levin, O’Donnell, \& Kratochwill, 2003;

Kratochwill \& Levin, 2010a). For example, in consideration of drawing valid inferences from case studies, such factors as the number and type of assessment occasions, projections of performance of behavior, number of treatments, among other dimensions can be used to improve the validity of the study. The contribution of this standard to practice-based evidence is to help with causal inference when examining the intervention outcomes in a practice context.

Example application. Reuther, Davis, Moree, and Matson (2011) reported a case study involving the use of a modular cognitive behavioral treatment of selective mutism that demonstrates how some basic case study design features can be used to improve the evidence base in practice. These authors adopted an evidence-based intervention focused on Modular Cognitive-Behavioral Therapy for Childhood Anxiety Disorders (Chorpita, 2007) based on the relationship of selective mutism to anxiety. Various treatment procedures were used including psychoeducation, exposure, cognitive restructuring, social skills training, and relapse prevention procedures. The authors adopted various outcome measures including fear hierarchy ratings, self- and parent-report ratings, and interviews. They reported that the treatment outcome was generally positive at the end of 21 sessions and at post-treatment and at 1and 6-month follow-up. Among the various procedures that can improve the creditability of case study research, the authors embraced several of these variables that made their report valuable for practice-based evidence. They introduced the treatment in the face of a chronic problem, adopted a standardized treatment manual, used well-developed assessment measures, and repeated these measures across time to gauge outcomes, scheduled follow up assessment, among other factors. However, in their case report the authors used an A design with repeated monitoring across the outcome measures. One major improvement that could be scheduled into this type of case study is developing a 
baseline assessment in the design, thereby constructing an AB design (Kazdin, 2011). Such a procedure builds in a comparison into the research procedures and when complemented with a randomized start time for the treatment, can increase validity considerably (Kratochwill \& Levin, 2010b).

Assessments to measure intervention outcomes. One dimension of practicebased evidence is the use of systematic measures to evaluate intervention outcomes. The case for the use of systematic measures in practice can be based on three important assumptions (Kazdin, 2008). First, clinical evaluation is necessary to determine if client outcomes are positive and consistent with the findings of the original EBP research. Second, ongoing assessment of client progress allows modifications and options for determining changes in the intervention as well as the potential for monitoring any negative side effects of the intervention (itself an important contribution of practice-based evidence). Finally, evaluation can complement "clinical judgment" and extends beyond traditional protocols for measurement used in research thereby allowing study of how the practitioner used clinical expertise and judgment in treatment.

Development of cost-effective and time-efficient measures that can be used in school practice is a high priority for practice-based evidence (Jenson-Doss \& Hawley, 2010). One example option for evaluation of practice with an emphasis on schools has been presented through Outcomes; Planning, Monitoring, Evaluating (Outcomes: PME) (Stoiber \& Kratochwill, 2002). Outcomes: PME can be linked to intervention at the level of the individual, group, or system and can be implemented by a psychologist providing services as a consultant or through a problemsolving team. Measurement options involve a variety of strategies including goal attainment scaling, which may be particularly cost- and time-efficient for practitioners. Outcomes: PME can be implemented in a case study format and is therefore compatible with the methodological 
PRACTICE-BASED EVIDENCE FOR CHILDREN AND ADOLESCENTS

standards for generating empirical knowledge from practice including action research and participatory action research (Nastasi et al., 2004). Whatever measures are used, meeting high standards of reliability and validity is critical.

Evaluation of intervention outcomes is compatible with current practices in prevention practice and RtI in particular (Glover et al., 2007). Within the RtI movement, most psychologists practicing in schools have been exposed to the importance of evaluating interventions in multiple ways and, in fact, many have been educated within a scientistpractitioner model where this dimension of practice is featured (e.g., Hayes et al., 1999). Many psychologists have also been exposed to the work in applied behavior analysis that has traditionally emphasized the importance of data-based decision making as interventions are implemented in practice. RtI systems depend very heavily on effective progress monitoring measures (or outcome assessment) to both identify students (screening) and to make decisions about the effectiveness of an intervention and movement within and across tiers (progress monitoring). Although considerable work needs to be done to advance reliability, validity, and assessment utility of progress monitoring approaches in both academic and social/emotional domains (Reynolds \& Shaywitz, 2009), there is growing evidence that the results of various standardized tests used in curriculum-based measurement in oral reading, for example, are strongly correlated with one another (see Reschly, Busch, Betts, Deno, \& Long, 2009). Furthermore, recent research has advanced work on estimating standard error metrics in curriculum-based measurement (Christ, 2006).

Because RtI systems typically include a progress-monitoring assessment component that is an integral part of the system of services, outcome measures may be readily available and can be used at relatively low time and cost to help make decisions about effective prevention and 
intervention (Riley-Tillman \& Burns, 2009). For example, measures of progress monitoring in academic domains are now widely available and web-based (see information from the National Center on Student Progress Monitoring, http://www.studentprogress.org/ and the National Center on Response to Intervention, www.studentprogress.org/chart/chart.asp ). In addition, systematic assessment within various behavioral and mental health outcomes can be readily applied such as in positive behavior support and the SWIS system (Horner, Sugai, Todd, \& Lewis-Palmer 2005). Other options in clinical intervention are emerging as will be illustrated below. These options make the role of the practitioner in generating evidence all the more likely and credible for influencing future research and practice.

Example application. As an example relevant to clinical intervention, the Child STEPs model for treatment of youth mental health problems uses a multi-component approach called Modular Approach to Treatment of Children with Anxiety, Depression, Trauma, or Conduct Problems (MATCH: ADTC; Chorpita \& Weisz, 2009), combined with a clinical information system to inform practitioners about their young clients' response to intervention, week-by-week (Weisz \& Chorpita, 2011). MATCH-ADTC consists of 33 modules encompassing components of evidence-based interventions for the four clusters of disorders and problems embodied within the name of the protocol; for example, one module focuses on learning to calm oneself at times of stress, and another focuses on identifying and modifying anxious or depressive thoughts. Decisions about which modules to use, when, and for how long before switching to another, are guided by a regular flow of response to intervention information in the form of a web-based client dashboard like the one shown in Figure 3 (see Chorpita, Bernstein, \& Deleiden, 2008). The upper panel of the dashboard shows how the child is responding to treatment, based on weekly reports of caregiver and youth on a the Brief Problem Checklist (Chorpita et al., 2010) a standardized measure of 
internalizing and externalizing symptoms; with a click of the mouse, the upper panel will also display caregiver and youth weekly reports on Top Problems (Weisz et al., 2011), a measure on which caregiver and youth (separately) rate the severity of the three problems each identified as most important at the outset of treatment. Improvement is indicated by declines in parent and child ratings on each measure over time. The middle panel shows which modules were used in treatment, and when. Circles indicate which modules were planned (e.g., in supervision) for each week; filled circles indicate that plans were carried out, empty circles that the planned modules were not carried out. The lower panels show who attended the sessions and whether certain procedures of special interest (e.g., role plays, homework) were used. This particular dashboard shows high problem levels up to about day 85, then a drop thereafter, with occasional rises, but the overall pattern shows a child whose response to intervention was quite favorable from the beginning of treatment to the end. The precise timing of the changes can be matched to days in treatment and to the particular modules used in particular weeks.

Because this particular form of progress monitoring is web-based, it provides easy access by clinicians and clinical supervisors to information about client progress, and it allows easy information sharing, even by phone, as clinicians in a supervision group all log on and view the dashboards for the children in their caseloads. The dashboards also inform clinical supervision by distinguishing between youngsters who are and are not improving. The system allows clinicians to navigate through treatment episodes efficiently, using evidence on treatment response to guide decisions about how long to continue particular modules, when to change direction, and when to begin planning for termination. In addition to such case-level applications, it is also possible to aggregate dashboard reports across cases to produce summary information for, say, a therapist's 
PRACTICE-BASED EVIDENCE FOR CHILDREN AND ADOLESCENTS

full caseload, all the cases of a particular clinical supervisor, or even all the cases in a particular clinic.

\section{Data-analysis procedures to assess the credibility of intervention effects.}

Determination of the intervention effect is an important component of practice-based research. In this regard, it is important to adopt appropriate and credible visual and statistical evidence standards compatible with the case study methodological format (Kratochwill \& Levin, 2010a). Generally, the practice-based researcher can use visual analysis and/or statistical procedures available for single-case designs. For example, the WWC Standards feature some major components of conducting a visual analysis (Horner et al., 2005; Kratochwill et al., 2010) that can be applied to the data.

Various statistical analysis procedures have also been recommended for single-case design, and some can be translated to case-study design when assessing intervention outcomes. For example, one class of randomization procedures can actually increase both internal and statistical conclusion validity of the research (Kratochwill \& Levin, 2010a, 2010b). As an illustration, in an $\mathrm{AB}$ design the practice-based researcher can determine the point of intervention on a random (as opposed to a clinician-generated) start point in the data series. Such a procedure would be possible with many of the progress-monitoring procedures now used in schools.

Single-case intervention outcome data can also be complimented with various clinical outcome indices that traditionally have been used in medical research but more recently converted for application in single-case designs (Parker \& Hagan-Burke, 2007). Such metrics as risk difference, relative risk, relative risk improvement, and odds ratio can be integrated into single-case design wherever there is a baseline (A) and intervention (B) phase. Although these metrics were introduced to complement formal and well-controlled single-case intervention 
research designs, they can serve the same function in practice based evidence work (as with an AB design). For example, when these metrics are applied in research and practice contexts, a comparison between these measures can serve in the role of mapping differences (if any) between research outcomes on an evidence-based practice and practice-based intervention outcomes.

Example application. Returning to the Reuther et al. (2011) case study involving the use of a modular cognitive behavioral treatment of selective mutism, we noted that one major improvement that could be scheduled into this research study is adopting an AB design. In addition to improving the basic validity of the report, an AB design structure allows for some possible and more formal data analysis procedures thereby strengthening the statistical conclusion validity of the results. In particular, if an AB design is used the possibility of adopting simulation modeling time-series analysis (Borckhardt, et al., 2008), randomization tests (with a randomized start point in the series; Kratochwill \& Levin, 2010b), and some of the clinical outcome indices noted above. Thus, adding a baseline comparison phase has a number of distinct methodological and statistical advantages for the use of single-case design in generating practicebased evidence.

\section{Dissemination of Findings from Practice: Implications for Prevention- Intervention Practice, Policy, and Directions for Research}

For traditional clinical trial research, applying knowledge that is gained systematically to improve public health and education is a well-documented priority. National organizations, the federal government, states, and provider organizations have created resources, initiatives, and other approaches to assure that research-informed practices are widely used. This focus includes state-based initiatives to disseminate EBPs, registries of effective programs (e.g., WWC), 
development of measurement feedback systems for integration in clinical practice (i.e., Kelley \& Bickman, 2010; Garland et al., 2010; Lambert, et al., 2003); and the establishment of organizations to disseminate effective practices through high quality training and coaching application (e.g., the REACH Institute, www.thereachinstitute.org). To advance research on dissemination and implementation of EBPs, several critical issues must also be addressed at the policy level and in research; these issues are mentioned hear with the hope that they can be addressed by the school psychology leadership.

First, a broad framework for knowledge development in practice-based evidence is needed. Implementation of practice-based evidence is itself an important research agenda that should be given priority in our journals, but a roadmap of what practice-based evidence research to conduct on what topics is needed. Evidence-based intervention knowledge about children's mental health and the promotion of academic competencies and achievement has grown exponentially over the past 15 years. The challenge is to take this evidence base and fit it into the prevailing and predominant contexts surrounding children with academic and mental health needs. The multiple levels of the school context require sophisticated methods, research designs, assessment strategies, and decision-making tools to inform the uptake of these newer practices. A broad systems approach recommended by the Task Force can facilitate this agenda, and a meta-systems model can further help guide research in this area especially when embracing practice-based evidence initiatives outlined in this paper (Kazak et al., 2010).

Second, it will be critical to identify sources of funding where the researcher-practitioner partnership is a centerpiece of the research process elaborated in this paper. The EBP research enterprise largely exists to fund researchers but researcher-practitioner partnerships must be fostered and supported with funding to advance the science of EBP. Advocating for this 
partnership in funded research to the Institute of Education Sciences and the National Institute of Mental Health would be a desirable agenda in the future, although other sources might be considered such as private foundations with a stake in EPBs. Some conceptual and empirical models have been advanced that provide leads for how this process might be supported. For example, Fantuzzo, McWayne, and Bulotsky (2003) provided a framework for advancing mental health science and practice with a partnership-based component to advance implementation. Among other issues the partnership component can help address important barriers to implementation of EBPs including for example, why participant communities and especially schools, say "no" to research collaboration.

Third, it will be important for school psychology journals to promote publication of research findings generated from practice-based approaches. An example of this option was already established in the Journal of Clinical Child Psychology with a section devoted to intervention research conducted with relaxed methodological standards and in a practice context. For example, Cunningham, Ellis, and Naar-King (2010) present the results of Multisystemic Therapy (MST), an intervention adapted to treat obesity, as applied to an obese 15-year-old African American boy. The study pointed the way to some important contextual variables to consider in future adaptations of MST to this population of students. Other recent examples published in this series can also be useful to practitioners such as the treatment of ADHD in a preschool child (Verduin, Abikoff, \& Kurtz, 2008) and modular cognitive behavioral treatment of selective mutism as featured in our case illustration above (Reuther et al., 2011). We would encourage school psychology journal editors to adopt a similar option in their editorial policies to promote practice-based evidence investigations. In this process some attention to the criteria 
advanced in this manuscript could be considered especially when the work represents a partnership with academic and practicing psychologists.

Fourth, journals in the school psychology field should consider adopting policies that allow publication of negative results, both from highly controlled research trials and in our context, practice-based research. It is possible that some intervention practices in common use in schools actually have negative results research that casts doubt on the effectiveness of these various practices and procedures. With the scientific bias against publishing negative results studies, this information cannot be featured to affect practice (Kratochwill, Stoiber, \& Gutkin, 2001). The importance of negative results and negative side effects noted as paramount in the psychotherapy field (e.g., Barlow, 2010) is especially relevant in school psychology practice as RtI is implemented with diverse venues across school districts in this country. Practice-based evidence research may further shed light on why a particular intervention is not effective under certain practice conditions and the potential negative side effects of interventions.

Fifth, although the clinical outcome metrics discussed above can improve intervention outcome reporting in practice-based evidence research (Parker \& Hagan-Burke, 2007), some standards or common effect-size measures (e.g., standardized mean difference, percent of variance accounted for) must be developed for single-case designs (and in our context case study designs), given the limitations of current options (Shadish \& Rindskopf, 2007; Shadish, Rindskopf, \& Hedges, 2008). This research agenda will hopefully result in some degree of consensus on appropriate single-case effect-size measures. Such an agenda is critical for eventual dissemination of results based on designating prevention- interventions that are adapted or better suited for particular ecologies.

\section{Conclusion}


In this paper we have recommended that traditional experimental research be complimented with information developed from practice-based evidence. In particular, we recommended consideration of several issues when practice-based evidence is used to embellish the evidence base of scientific knowledge: (a) systematic evidence searching and adoption of evidence-based prevention and intervention practices, (b) implementation and adherence to intervention integrity, (c) invoking standards for drawing inferences from interventions, (d) using quality assessments to measure outcomes, and (e) adopting formal data analysis procedures to assess intervention outcomes. Developing practice-based evidence can move the EBP science forward while also enhancing adoption, implementation, and dissemination. What sets practicebased evidence research apart from traditional methodologies is that this research activity is primarily implemented by practitioners working in partnership with researchers to extend the knowledge base on implementation in the natural context of practice. The various criteria advanced here can help address our understanding of structural and process variables that affect adoption, implementation, and outcomes as compared to traditional research evidence attesting to an EBP. It is of particular importance as both APA task forces called for EBP that features clinical expertise and consideration of the client's characteristics, culture, and preferences as part of the process. Implementation and dissemination of better practices to improve children's mental health and achievement depends on models, theories, and practices to support innovation. The tools exist, but they must be put to good use. 


\section{References}

Atkins, M. S., Frazier, S. L., Leathers, S. J., Graczyk, P. A., Talbott, E., Adil, J. A., Jakobsons, L., Marinez-Lora, A., Bell, C. C., Gibbons, R. B., Demitras, H. (2008). Teacher key opinion leaders and mental health consultation in urban low-income schools. Journal of Consulting and Clinical Psychology, 76, 905-908.

American Psychological Association Presidential Task Force on Evidence-based Practice (2006). Evidence-based practice in psychology. American Psychologist, 61, 271-285.

American Psychological Association Task Force on Evidence-Based Practice for Children and Adolescents. (2008). Disseminating evidence-based practice for children and adolescents: A systems approach to enhancing care. Washington, DC: American Psychological Association.

Barlow, D. H., Nock, M. K., \& Hersen, M. (2009). Single-case experimental designs. Strategies for studying behavior change ( $3^{\text {rd }}$ ed.). Boston, MA: Allyn \& Bacon.

Bickman, L. (2008). A measurement feedback system (MFS) is necessary to improve mental health outcomes. Journal of the American Academy of Child and Adolescent Psychiatry, 47, $1114-1119$.

Borckardt, J. J., Nash, M. R., Murphy, M. D., Moore, M., Shaw, D., \& O’Neil, P. (2008). Clinical practice as natural laboratory for psychotherapy research. American Psychologist, $63,77-95$.

Burns, M. K. (2011). School psychology research: Combining ecological theory and prevention science. School Psychology Review, 40, 132-139.

Chorpita, B. F. (2007). Modular cognitive-behavioral therapy for childhood anxiety disorders. New York: Guilford. 
Chorpita, B.F., Bernstein, Adam, Daleiden, Eric L., \& The Research Network on Youth Mental Health. (2008). Driving with roadmaps and dashboards: Using information resources to structure the decision models in service organizations. Administration and Policy in Mental Health and Mental Health Services Research, 35, 114-123.

Chorpita, B.F., Reise, S., Weisz, J.R., Grubbs, K., Becker, K.D., Krull, J.L., and the Research Network on Youth Mental Health (2010). Evaluation of the Brief Problem Checklist: Child and caregiver interviews to measure clinical progress. Journal of Consulting and Clinical Psychology, 78, 526-536.

Chorpita, B.F., \& Weisz, J.R. (2009). Modular Approach to Therapy for Children with Anxiety, Depression, Trauma, or Conduct Problems (MATCH-ADTC). Satellite Beach, FL: PracticeWise, LLC.

Christ, T. J. (2006). Short-term estimates of growth using curriculum-based measurement of oral reading fluency: Estimating standard error of the slope to construct confidence intervals. School Psychology Review, 35, 128-133.

Cunningham, P. B., Ellis, D. A., \& Naar-King, S. (2010). Treating pediatric obesity using an empirically supported treatment: A case study. Journal of Clinical Child \& Adolescent Psychology, 39, 141-150.

Epstein, M., Atkins, M., Cullinan, D., Kutash, K., \& Weaver, K. (2008). Reducing behavior problems in the elementary school classroom. Washington, DC: Institute of Education Sciences.

Elliott, S. N., Huai, N., \& Roach, A. T. (2007). Universal and early screening for educational difficulties: Current and future approaches. Journal of School Psychology, 45, 137-161. 
Falzon, L., Davidson, K. W., \& Bruns, D. (2010). Evidence-searching for evidence-based psychology practice. Professional Psychology: Research and Practice, 41, 550-557.

Fantuzzo, J., McWayne, C., \& Bulotshy, R. (2003). Forging strategic partnerships to advance mental health science and practice for vulnerable children. School Psychology Review, 32, 17-37.

Feldstein, A. C., \& Glasgow, R. E. (2008). A Practical, Robust Implementation and Sustainability Model (PRISM). Joint Commission Journal on Quality and Patient Safety, 34, $228-243$.

Fixsen, D.L., Naoom, S.F., Blasé, K.A., Friedman, R.M., \& Wallace, F. (2005) Implementation research: A synthesis of the literature. Tampa: University of South Florida, Louis de la Parte Florida Mental Health Institute.

Forman, S.G., Olin, S.S., Hoagwood, K.E., Crowe, M., \& Saka, N. (2009). Evidence-based interventions in schools: Developer's views of implementation barriers and facilitators. School Mental Health, 1, 26-36.

Frazier, S. L., Formoso, D., \& Birman, D., \& Atkins, M. S. (2008). Closing the research to practice gap: Redefining feasibility. Clinical Psychology: Science and Practice, 15, 125-129.

Frazier, S. L., Cappella, E., \& Atkins, M. S. (2007). Linking mental health and after school systems for children in urban poverty. Preventing problems, promoting possibilities. Administration and Policy in Mental Health and Mental Health Services Research, 34, 389399.

Frazier, S. L., Adil, J. A., Atkins, M. S., Gathright, T., \& Jackson, M. (2007). Can't have one without the other: Mental health providers and community parents reducing barriers to services for families in urban poverty. Journal of Community Psychology, 35, 435-446. 
Freiberg, H. J., \& Laponte, J. M. (2006). Research-based programs for preventing and solving discipline problems. In C. M. Evertson and C. S. Weinstein (Eds.). Handbook of classroom management: Research, practice, and contemporary issues (pp.735-786). Mahwah, NJ:

Erlbaum.

Fuchs, D., \& Fuchs, L. S., \& Stecker, P. M. (2010). The "blurring” of special education in a new continuum of general education placements and services. Exceptional Children, 76, 301323.

Garland, AF., Bickman, L., Chorpita, BF. (2010). Change What? Identifying Quality Improvement Targets by Investigating Usual Mental Health Care. Admiration and Policy in Mental Health, 37:15-26.

Glisson, C. \& James, L. R. (2002). The cross-level effects of culture and climate in human service teams. Journal of Organizational Behavior, 23, 767-794.

Glisson, C., Landsverk, J., Schoenwald, S. K., Kelleher, K., Hoagwood, K. E., Mayberg, S., et al. (2008). Assessing the organizational social context (OSC) of mental health services: Implications for implementation research and practice. Administration and Policy in Mental Health and Mental Health Services Research, 35(1), 98-113.

Glover, T. A., \& DiPerna, J. C. (2007). Service delivery for response to intervention: Core components and directions for future research. School Psychology Review, 36, 526-540.

Glover, T. A., Diperna, J. C., \& Vaughn, S. (2007). Introduction to the special series on service delivery systems for response to intervention: Considerations for research and practice. School Psychology Review, 36, 523-525.

Green, L.W. (2006). Public health asks of systems science: To advance our evidence 
PRACTICE-BASED EVIDENCE FOR CHILDREN AND ADOLESCENTS

based practice, can you help us get more practice-based evidence? American Journal of Public Health, 96, 406-409.

Greenwood, C. W., Maheady, L., \& Carta, J. J. (1991). Peer tutoring programs in the regular education classroom. In G. Stoner, M. R. Shinn, \& H. M. Walker (Eds). Interventions for achievement and behavior problems ( $1^{\text {st }}$ ed., pp. 179-200). Washington, DC: National Association of School Psychologists.

Greenwood, C. R., Kamps, D., Terry, B. J., \& Linebarger, D. L. (2007). Primary intervention: A means of preventing special education? In D. Haager, J. Klingner, \& S. Vaughn (Eds.). Evidence-based practices for response to intervention (pp. 73-103). Baltimore, MD: Brooks Publishing.

Greenwood, C. R., Reynolds, S., Abbott, M., \& Tapia, Y. (2004). Together we can: Class-Wide Peer Tutoring Learning Management System (CWPT-LMS). Kansas City, KS: Juniper Gardens Children's Project, University of Kansas.

Gresham, F. M. (1989). Assessment of treatment integrity in school consultation and prereferral intervention. School Psychology Review, 18, 37-50.

Hagermoser Sanetti, L. M., \& Kratochwill, T. R. (2008). Treatment integrity in behavioral consultation: Measurement, promotion, and outcomes. International Journal of Behavioral Consultation and Therapy, 4, 95-114.

Hagermoser Sanetti, L. M., \& Kratochwill, T. R. (in press). Treatment integrity assessment in the schools: An evaluation of the Treatment Integrity Planning Protocol (TIPP). School Psychology Quarterly.

Hawkins, R. P., Mathews, J. R. (1999). Frequent monitoring of clinical outcomes: Research and accountability for clinical practice. Education \& Treatment of Children, 22, 117-135. 
Hayes, S.C., Barlow, D.H., \& Nelson, G.R. (1999). The scientist practitioner: Research and accountability in the age of managed care ( $2^{\text {nd }}$ ed.). Needham Heights, MA: Allyn and Bacon.

Hoagwood., K., Cavaleri, M., Olin, S., Burns, BJ., Slaton, E., Gruttadaro, D., Hughes, R. (2010). Family Support in Children's Mental Health: A Review and Synthesis. Clinical Child and Family Psychology Review, 13, 1-45.

Horner, R. H., Carr, E. G., Halle, J., McGee, G., Odom, S., Wolery, M. (2005). The use of single subject research to identify evidence-based practice in special education. Exceptional Children 71, 165-179.

Horner, R. H., Sugai, G., Todd, A. W., \& Lewis-Palmer, T. (2005) School-wide positive behavior support: An alternative approach to discipline in schools. In L. M. Bambara \& L. Kern (Eds.), Individualized supports for students with problem behaviors (pp. 359390). New York: Guilford Press.

Huang, L., Stroul, B., Friedman, R., Mrazek, P., Friesen, B., Pires, S., \& Mayberg, S. (2005). Transforming mental health care for children and their families. American Psychologist, 60, $615-627$.

Jenson-Doss, A., \& Hawley, K. M. (2010). Understanding barriers to evidence-based assessment: Clinician attitudes toward standardized assessment tools. Journal of Clinical Child \& Adolescent Psychology, 39, 885-896.

Kazak, A. E., Hoagwood, K., Weisz, J., Hood, K., Kratochwill, T. R., Vargas, L. A., \& Banez, G. A. (2010). A meta-systems approach to evidence-based practice for children and adolescents. American Psychologist, 65, 85-97.

Kazdin, A. E. (1982). Single-case research designs: Methods for clinical and applied settings. 
PRACTICE-BASED EVIDENCE FOR CHILDREN AND ADOLESCENTS

New York: Oxford University Press.

Kazdin, A. E. (2011). Single-case research designs: Methods for clinical and applied settings (2nd ed.). New York: Oxford University Press.

Kazdin, A.E. (2008). Evidence-based treatment and practice: New opportunities to bridge clinical research and practice, enhance the knowledge base, and improve patient care. American Psychologist, 63, 146-159.

Kazdin, A. E., Kratochwill, T. R., \& Vanden Bos, G. (1986). Beyond clinical trials:

Generalizing from research to practice. Professional Psychology: Research and Practice, 3, 391-398.

Kellam, S. G., Rebok, G. W., Ialongo, N., \& Mayer, L. S. (1994). The course and malleability of aggressive behavior from early first grade into middle school: Results of a developmental epidemiologically-based preventive trial. Journal of Child Psychology and Psychiatry, $25,259-281$.

Klimes-Dougan, B., August, G. J., Lee, C-Y S., Realmuto, G. M., Bloomquist, M. L., Horowitz, J. L., \& Eisenberg, T. L. (2009). Practitioner and site characteristics that relate to fidelity of implementation: The early risers prevention program in a going-to-scale intervention trial. Professional Psychology: Research and Practice, 40, 467-475.

Kratochwill, T. R. (1985). Case study research in school psychology. School Psychology Review, 14, 204-215.

Kratochwill, T. R. (2006). Evidence-based interventions and practices in school psychology: The scientific basis of the profession. In R. Subotnik \& H. Walberg (Eds.), The scientific basis of educational productivity (pp. 229-267). Washington, DC: American Psychological Association. 
PRACTICE-BASED EVIDENCE FOR CHILDREN AND ADOLESCENTS

Kratochwill, T. R. (2007). Preparing psychologists for evidence-based practice: Lessons learned and challenges ahead. American Psychologist, 62, 826-843.

Kratochwill, T. R., \& Levin, J. R. (2010a). Methodological and data analysis innovations for single-case intervention designs: Advancing the standards for research. Grant proposal submitted to the Institute for Education Science, June, 2010.

Kratochwill, T. R., \& Levin, J. R. (2010b). Enhancing the scientific credibility of single-case intervention research: Randomization to the rescue. Psychological Methods, 15, 122-144.

Kratochwill, T. R., \& Piersel, W. C. (1983). Time-series research: Contributions to empirical clinical practice. Behavioral Assessment, 5, 165-176.

Kratochwill, T. R., Clements, M. A., \& Kalymon, K. M. (2007). Response to intervention: Conceptual and methodological issues in implementation. In S. R. Jimerson, M. K. Burns, \& A. M. VanDerHeyden (Eds.), The handbook of response to intervention: The science and practice of assessment and intervention. New York: Springer.

Kratochwill, T. R., Stoiber, K. C., \& Gutkin, T. B. (2001). Empirically supported interventions in school psychology: The role of negative results in outcome research. Psychology in the Schools, 37, 399-413.

Kratochwill, T. R., Hitchcock, J., Horner, R. H., Levin, J. R., Odom, S. L., Rindskopf, D. M \& Shadish, W. R. (2010). Single case designs technical documentation. In What Works Clearinghouse: Procedures and standards handbook (version 2.0). Retrieved from What Works Clearinghouse website: http://ies.ed.gov/ncee/wwc/pdf/wwc_procedures_v2_standards_handbook.pdf Lambert, M.J., Whipple, J.L., Hawkins, E.J., Vermeesch, D.A., Nielsen, S.L., \& Smart, D.W. 
PRACTICE-BASED EVIDENCE FOR CHILDREN AND ADOLESCENTS

(2003). Is it time for clinicians to routinely track patient outcome? A meta-analysis. Clinical Psychology: Science and Practice, 10, 288-301.

Levin, J. R., O'Donnell, A. M., \& Kratochwill, T. R. (2003). Educational/psychological intervention research. In I. B. Weiner (Series Ed.), W. M. Reynolds \& G. E. Miller (Volume Eds.). Handbook of psychology: Vol. 7. Educational psychology (pp. 557-581). New York: Wiley.

Levitt, J. M., Saka, N., Hunter Romanelli, L., \& Hoagwood, K. (2007). Early identification of mental health problems in schools: The status of instrumentation. Journal of School Psychology, 45, 163-191.

Lewis, T. J., Newcomer, L. L., Trussell, R., \& Richter, M. (2006). School-wide positive behavior support: Building systems to develop and maintain appropriate social behavior. In C. M. Evertson and C. S. Weinstein (Eds.). Handbook of classroom management: Research, practice, and contemporary issues (pp.833-854). Mahwah, NJ: Erlbaum.

Lilienfeld, S. O., Ammirati, R., \& David, M. (in press). Distinguishing science from pseudoscience in school psychology (part 1): Science and scientific thinking as safeguards against human error. Journal of School Psychology,

Lockman, J. E., Powell, N. P., Boxmeyer, C. L., Qu, L., Wells, K. C., \& Windle, M. (2009). Implementation of a school-based prevention program: Effects of counselor and school characteristics. Professional Psychology: Research and Practice, 40, 476-482.

McFall, R. M. (1991). Manifesto for a science of clinical psychology. The Clinical Psychologist, $44,65-88$.

McLeod, B. D., Southam-Gerow, M. A., \& Weisz, J. R. (2009). Conceptual and methodological issues in treatment integrity measurement. School Psychology Review, 38, 541-546. 
PRACTICE-BASED EVIDENCE FOR CHILDREN AND ADOLESCENTS

Morgan, D. L., \& Morgan, R. K. (2001). Single-participant research design: Bringing science to managed care. American Psychologist, 56, 119-127.

Nastasi, B. K., Moore, R. B., \& Varjas, K. M. (2004). School-based mental health services: Creating comprehensive and culturally specific programs. Washington, DC: American Psychological Association.

Newman, D. W., Kellett, S. C. \& Beail, N. (2003). From research and development to practice based evidence: Clinical governance initiatives in a service for adults with intellectual disabilities and mental health needs. Journal of Intellectual Disability Research, 47, 6874.

Norcross, J. C., Hogan, T. P., \& Koocher, G. P. (2008). Clinician's guide to evidence-based practices. New York: Oxford Press.

Parker, R. I., \& Hagan-Burke, S. (2007). Single case research results as clinical outcomes. Journal of School Psychology, 45, 637-653.

Power, T. J., Blom-Hoffman, J., Clarke, A. T., Riley-Tillman, T. C., Kelleher, C., \& Manz, P. H. (2005). Reconceptualizing intervention integrity: A partnership-based framework for linking research with practice. Psychology in the Schools,42(5), 495-507.

Reschly, A. L., Busch, T. W., Betts, J., Deno, S. L., \& Long, J. D. (2009). Curriculum-based measurement oral reading as an indicator of reading achievement: A meta-analysis of the correlational evidence. Journal of School Psychology, 47, 427-469.

Reschly, D. J., \& Bergstrom, M. K. (2009). Response to intervention. In T. B. Gutkin \& C. R. Reynolds (Eds.) The handbook of school psychology. New York: Wiley.

Reuther, E. T., Davis, T. E., III, Moree, B. N., \& Matson, J. L. (2011). Treating selective mutism 
PRACTICE-BASED EVIDENCE FOR CHILDREN AND ADOLESCENTS

using modular CBT for child anxiety: A case study. Journal of Clinical Child \& Adolescent Psychology, 40, 156-163.

Reynolds, C. R., \& Shaywitz, S. E. (2009). Response to intervention: Ready or not? Or, from wait-to-fail to watch-them-fail. School Psychology Quarterly, 24, 130-145.

Riley-Tillman, T. C., \& Burns, M. K. (2009). Evaluating educational interventions: Single-case design for measuring response to intervention. New York: Guilford Press.

Robinson, S. L., \& Richod Griesemer, S. M. (2006). Helping individual students with problem behavior. . In C. M. Evertson and C. S. Weinstein (Eds.). Handbook of classroom management: Research, practice, and contemporary issues (pp.787-802). Mahwah, NJ: Erlbaum.

Shadish, W. R., \& Rindskopf, D. M. (2007). Methods for evidence-based practice: Quantitative synthesis of single-case designs. New Directions for Evaluation, 2007(113), 95-109.

Shadish, W. R., Rindskopf, D. M. \& Hedges, L. V. (2008). The state of the science in the metaanalysis of single-case experimental designs. Evidence-Based Communication Assessment and Intervention, 3, 188-196.

Sheridan, S. M., \& Kratochwill, T. R. (2008). Conjoint behavioral consultation: Promoting family-school connections and interventions ( $2^{\text {nd }}$ ed.). New York, NY: Springer Publishing.

Shieh, C. (2006, Fall). Practice-based evidence: How one nurse turned her day-to-day experiences into research. AWHONN Lifelines, 10(5), 375-378.

Stoiber, K.C., \& Kratochwill, T.R. (2002). Outcomes: Planning, monitoring, evaluating. San Antonio, TX: The Psychological Corporation.

Verduin, T. L., Abikoff, H., \& Kurtz, S. M. S. (2008). Evidence-based treatment of 
PRACTICE-BASED EVIDENCE FOR CHILDREN AND ADOLESCENTS

attention deficit/hyperactivity disorder in a preschool-aged child: A case study. Journal of Clinical Child \& Adolescent Psychology, 37, 477-485

Weisz, J.R. (2004). Psychotherapy for children and adolescents: Evidence-based treatments and case examples. Cambridge, UK: Cambridge University Press.

Weisz, J.R., \& Chorpita, B.F. (2011). Mod squad for youth psychotherapy: Restructuring evidence-based treatment for clinical practice. In P.C. Kendall (Ed.), Child and adolescent therapy: Cognitive-behavioral procedures, $4^{\text {th }}$ edition. New York: Guilford.

Weisz, J.R., Chorpita, B.F., Frye, A., Ng, M.Y., Lau, N., Bearman, S.K., Ugueto, A.M., Langer, D.A., Hoagwood, K., and the Research Network on Youth Mental Health (2011). Youth top problems: Using idiographic, consumer-guided assessment to identify treatment needs and track change during psychotherapy. Journal of Consulting and Clinical Psychology, 79, 369-380.

Weisz, J.R., Chu, B.C., \& Polo, A.J. (2004). Treatment dissemination and evidence-based practice: Strengthening intervention through clinician-researcher collaboration. Clinical Psychology: Science and Practice, 11, 300-307.

Weisz, J.R., Doss, A.J., Hawley, K.M. (2006). Evidence-based youth psychotherapies versus usual clinical care: A meta-analysis of direct comparisons. American Psychologist, 61, 671-689.

Weisz, J.R., Sandler, I.N., Durlak, J.A., \& Anton, B.S. (2005). Promoting and protecting youth mental health through evidence-based prevention and treatment. American Psychologist, $60,628-648$. 
1. Children and adolescents should receive the best available care based on scientific knowledge and integrated with clinical expertise in the context of patient characteristics, culture, and preferences. Quality care should be provided as consistently as possible with children and their caregivers and families across clinicians and settings.

2. Care systems should demonstrate responsiveness to youth and their families through prevention, early intervention, treatment, and continuity of care.

3. Equal access to effective care should cut across age, gender, sexual orientation, and disability, inclusive of all racial, ethnic, and cultural groups.

4. Effectively implemented EBP requires a contextual base, collaborative foundation, and creative partnership among families, practitioners, and researchers.

Source: American Psychological Association Task Force on Evidence-Based Practice for Children and Adolescents (2008). Disseminating Evidence-Based Practice for Children and Adolescents: A Systems Approach to Enhancing Care. Washington DC: American Psychological Association. 
PRACTICE-BASED EVIDENCE FOR CHILDREN AND ADOLESCENTS

TABLE 2. Dimensions of Science and Practice and Their Relationship to Research

\begin{tabular}{|c|l|l|}
\hline Dimension & \multicolumn{1}{|c|}{ Science } & Non-Science \\
\hline Research & Scientific Researcher & Non-Scientific Researcher \\
\hline Practice & Scientific Practitioner & Non-Scientific Practitioner \\
\hline & & \\
\hline
\end{tabular}


Table 3. Questions to Ask for Client, Intervention, Comparison and Outcome (CICO)

\begin{tabular}{|c|c|c|}
\hline & Ask yourself... & $\begin{array}{l}\text { Information to possibly } \\
\text { include in your question }\end{array}$ \\
\hline $\begin{array}{c}\text { C } \\
\text { Client }\end{array}$ & $\begin{array}{l}\text { Who is your client? } \\
\text { What is the client population of } \\
\text { interest? }\end{array}$ & $\begin{array}{l}\text { Your client's primary complaint, sex, } \\
\text { age, race, history (any factors that } \\
\text { will influence your search) }\end{array}$ \\
\hline $\begin{array}{c}\text { I } \\
\text { Intervention }\end{array}$ & $\begin{array}{l}\text { What are you planning to do for your } \\
\text { client? }\end{array}$ & $\begin{array}{l}\text { Specifics of your planned assessment or } \\
\text { treatment (any therapies you are } \\
\text { considering) }\end{array}$ \\
\hline $\begin{array}{c}\text { C } \\
\text { Comparison }\end{array}$ & $\begin{array}{l}\text { Is there an alternative to the } \\
\text { treatment? (Sometimes there is no } \\
\text { comparison.) }\end{array}$ & The alternative treatments, if any \\
\hline $\begin{array}{c}\text { O } \\
\text { Outcome }\end{array}$ & $\begin{array}{l}\text { What do you think will occur after } \\
\text { applying the treatment? }\end{array}$ & Your desired or hypothesized outcomes \\
\hline
\end{tabular}

Source: Adapted from Norcross, J. C., Hogan, T. P., \& Koocher, G. P. (2008). Clinician's guide to evidence-based practices. New York: Oxford Press. To be reproduced with permission. 


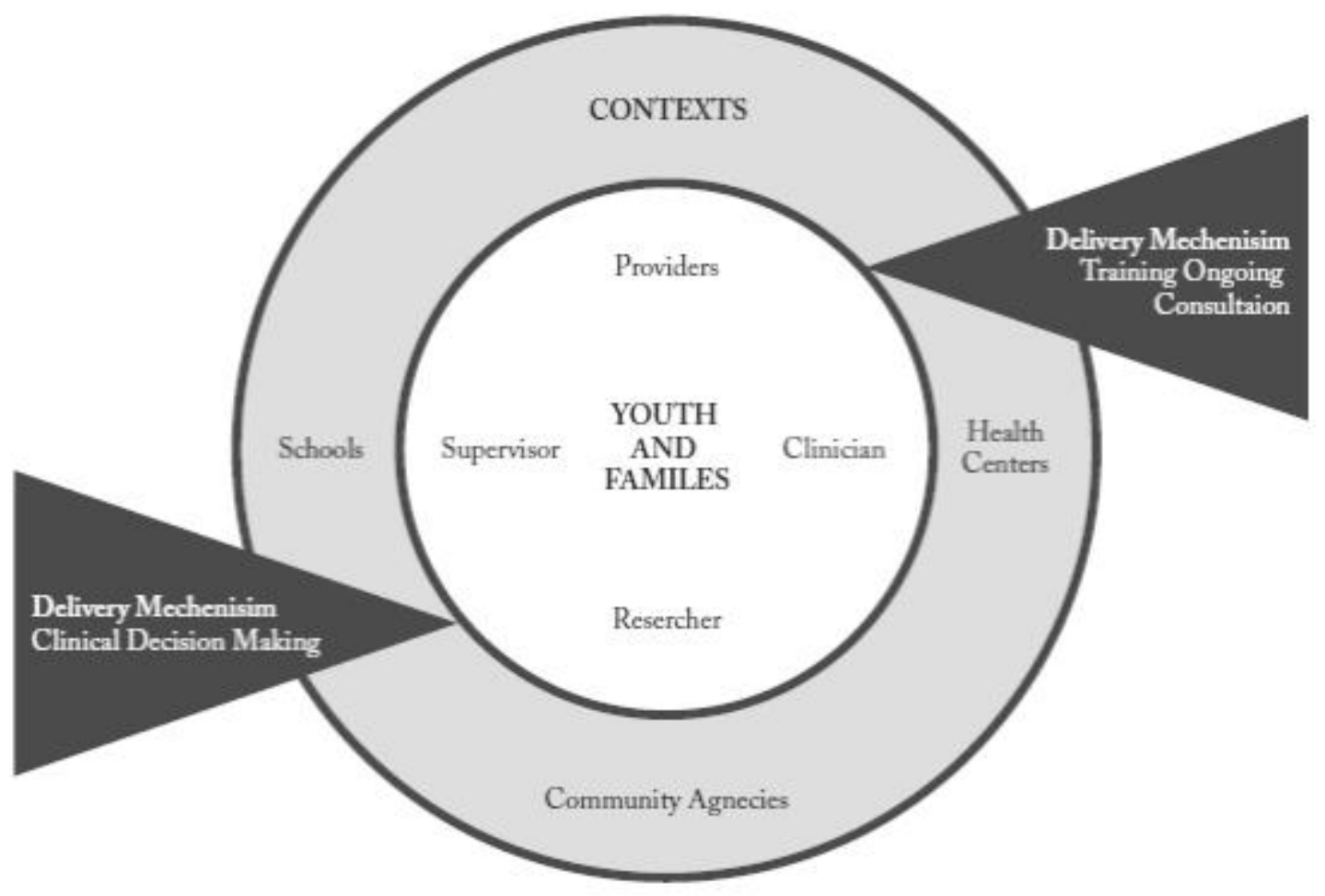

FIGURE 1: A systems social ecological framework guides conceptualization of EBP in youth

Figure 1. A Meta-Systems Social-Ecological Framework Guides Conceptualization of EBP in Youth. Source: American Psychological Association Task Force on Evidence-Based Practice for Children and Adolescents (2008). Disseminating Evidence-Based Practice for Children and Adolescents: A Systems Approach to Enhancing Care. Washington DC: American Psychological Association. 


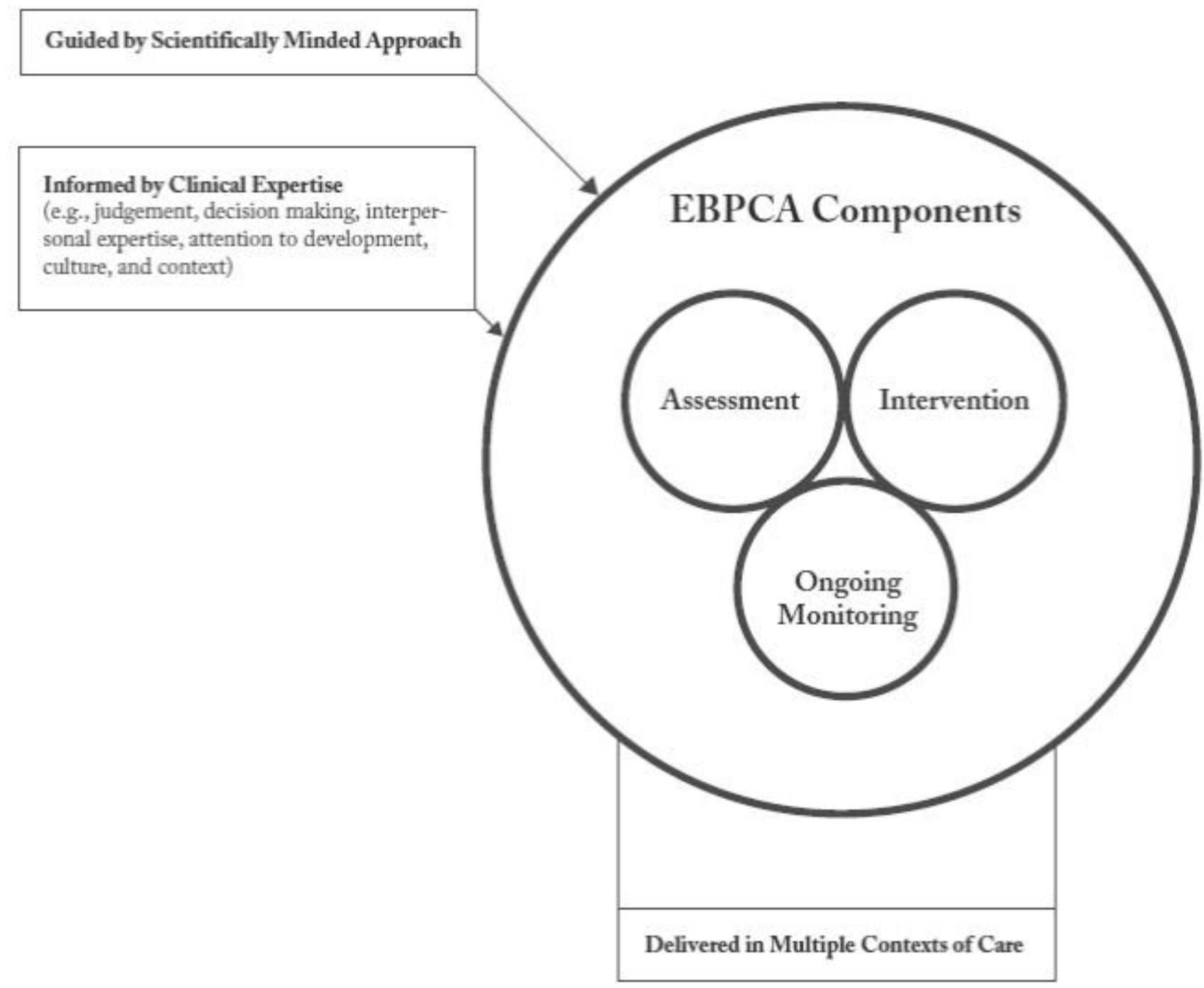

FIGURE 2: Three primary and reciprocal elements of an evidence-based clinical practice

Figure 2. Three Primary and Reciprocal Elements of an Evidence-Based Clinical Practice.

Source: American Psychological Association Take Force on Evidence-Based Practice for Children and Adolescents (2008). Disseminating Evidence-Based Practice for Children and Adolescents: A Systems Approach to Enhancing Care. Washington, DC: American Psychological Association. 


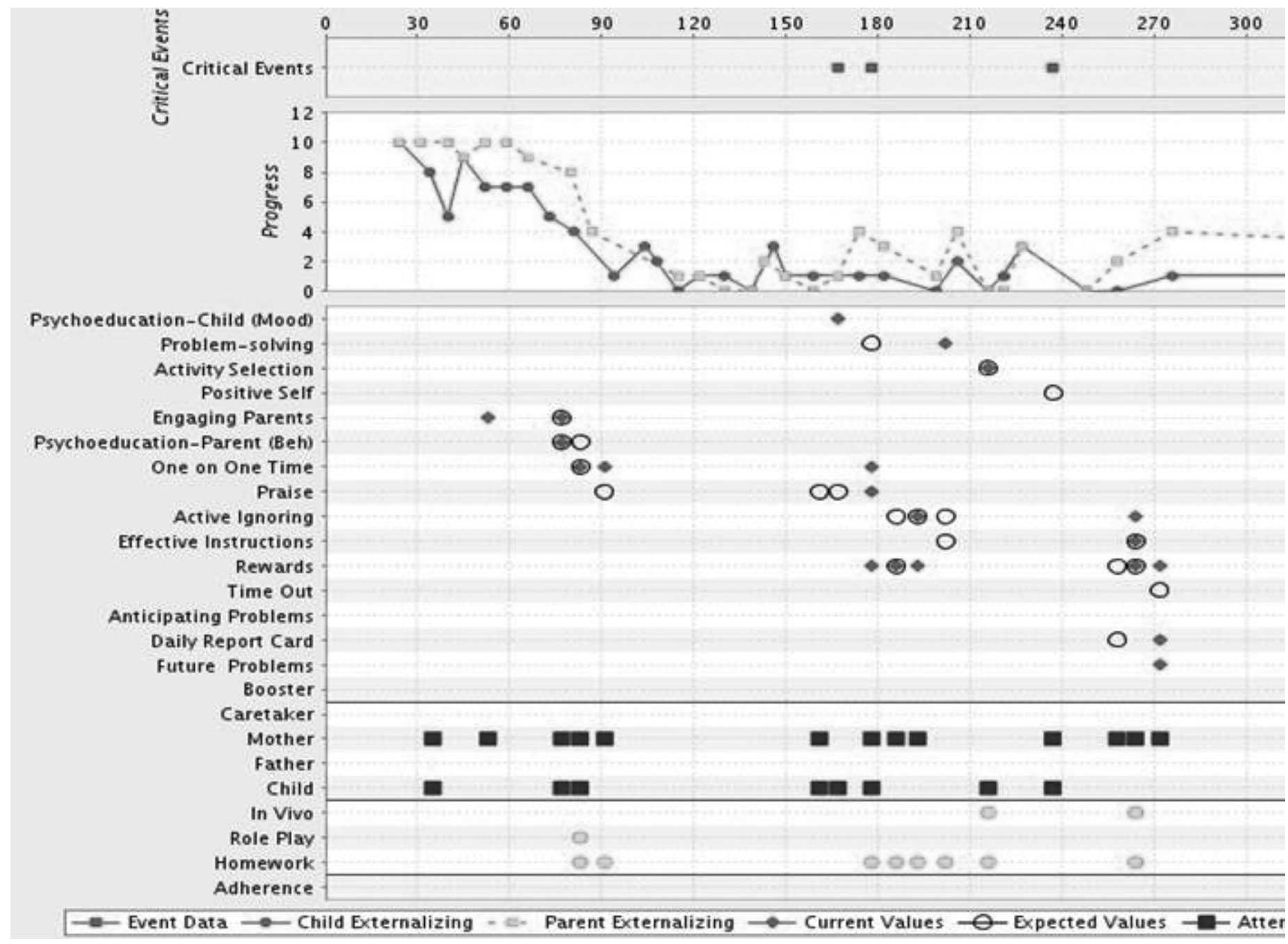

FIGURE 3. One approach to progress monitoring within response to intervention: The clinical dashboard used to monitor treatment response in the Child STEPs program. Research Network on Youth Mental Health. Reprinted with permission (see also Chorpita et al., 2008). 